\title{
Article
}

\section{Playability as Realism}

\author{
Jon Garthoff
}

In this essay I discuss how realism operates to constrain games, especially role-playing games, that take place in a fantasy milieu. The design of these games involves tradeoffs between two values, which are sometimes labeled "realism" and "playability". These values are ordinarily understood to be wholly independent and competing. Using resources drawn from John Rawls's conception of political theory as a search for a "realistic utopia”, I show how these values can instead be understood as aspects of the more general value of creating and conceiving a realistic fantasy through the medium of game play. I also explain how realism operates differently as a constraint on tabletop role-playing games from how it operates in realistic video games and live-action role-playing.

Keywords: fantasy, game balance, John Rawls, playability, realism, role-playing games.

\section{Introduction}

In this essay I discuss how realism operates to constrain works of creative fantasy. Most of the discussion concerns games, especially role-playing games, that take place in a fantasy milieu. The design of these games involves tradeoffs between two values, which are sometimes labeled "realism" and "playability". Realism consists in preserving the laws of nature of the real world and describing a fictional setting in detail. Playability consists in being simple enough for players to understand a game's principles and mechanics and for game play to proceed without onerous recordkeeping or rulebook consultation. There is some tension between these values. The more detailed a game becomes, the more realistically it can capture the events taking place within it; but the more detailed a game becomes, the more difficult it is to learn to play the game and to properly administer its rules during play. While this sort of tradeoff can arise in the design of any game, it is particularly pressing in role-playing games, for these games aspire to a greater degree of realism than most other game genres. Among role-playing games this question is especially pressing in the dominant fantasy genre, since significant departures from the actual world are needed in order to effect a fantasy, and accordingly realism cannot always be supplied by supposing the world of the game is like the actual world.

In what follows I use resources from utopian political philosophy to illuminate tradeoffs between realism and playability in the design of fantasy games. More specifically I discuss John Rawls's conception of political theory as a search for what he terms 
a "realistic utopia". ${ }^{1}$ Realism plays a perhaps surprisingly similar role limiting and informing the content of fantasies in these apparently unrelated domains; as I explain below, Rawls's understanding of realism as a limit on utopian thought illuminates how realism constrains fantasy games. Rawls understands the use and application of a conception of social justice - which he labels its "workability" - to be an aspect of its realism. ${ }^{2}$ Since what Rawls calls "workability” in a conception of justice is directly analogous to what game designers call "playability" of a game, this enables tradeoffs between realism and playability to be framed in a new way. Rather than thinking of these two values as independent, as I elaborate below, we can instead think of playability as itself a constituent of realism. What game designers call "realism" is realism about the world depicted in a game, and what they call "playability" is realism about the players of the game. When we view playability as in this way a kind of realism, we can view playability and realism as each helping constitute the realism of creating and conceiving a world through game play. This informs and illuminates judgments about how to balance these values to a greater extent than is possible when they are understood as independent from each other and traded off only in an intuitionistic fashion.

This discussion is related to, but importantly distinct from, current discussions about the nature or desirability of realistic experiences or simulations in video games. What is at issue in earlier discussions of tabletop pen-and-paper role-playing games is not the convincingness of a fantasy experience, as if these games were best understood as an anticipation of virtual reality technology. There was little emphasis on play-acting, and almost no emphasis on costume or props, in early role-playing. Live-action role-playing grew out of tabletop role-playing, becoming its own genre of game with much greater emphasis on realism of simulated experience. But this feature of live-action role-playing makes it a very different activity from tabletop role-playing. As I explain below, the most important questions of realism in tabletop role-playing games do not pertain to the realism of simulated experience; they pertain instead to the realism of a conceived fantasy world. ${ }^{3}$

The fullest statement of Rawls's political philosophy is found in Rawls (1971), and his second opus is Rawls (1993). Rawls elaborates the idea of a realistic utopia only in later work, however, in Rawls (1999), especially 11-16, and in Rawls (2001), especially 4-5 and 12-14.

See Rawls (1999), 12-13.

Jesper Juul (2005) explores issues about the realism of games. Gonzalo Frasca (2008) and Mary Flanagan (2009) also do so, with an eye toward the role of games in encouraging participation and criticism among a democratic citizenry. Although each of these authors considers more than one genre of game, each takes contemporary video games as a paradigm for discussion. 


\section{Playability versus Realism}

The first role-playing game, Dungeons \& Dragons, was co-created by Dave Arneson and Gary Gygax and published in $1974 .{ }^{4}$ That game and its successors in the same brand remain the most famous examples of the role-playing genre. This genre emerged from military simulation games, and both Arneson and Gygax were avid wargamers. The key innovation of role-playing games, setting them apart from earlier board games and military simulations, is that each player establishes a character or persona in the game which they subsequently develop over multiple sessions of play.

The most popular and influential role-playing game is Advanced Dungeons \& Dragons, and it was created by Gygax alone. (Somewhat confusingly the game later became known simply as Dungeons \& Dragons, as the original rules published under that title were discontinued; see footnote 5 below.) It shares the role-playing structure and heroic fantasy themes of the original Dungeons \& Dragons, but it has such vastly more detailed rules and reference resources that Gygax regarded it as a wholly separate game. ${ }^{5}$ It was first published in a series of books between 1977 and $1979 .{ }^{6}$ Interestingly the two classic role-playing games stand near opposite ends of the spectrum of rule complexity. The original Dungeons \& Dragons has a relatively simple design and a brief set of three rulebooks. It includes a smallish list of fantastic abilities which characters in the game might develop, and it deploys a relatively straightforward mechanism for resolving combat situations. The rulebooks are comparatively short and contain little information about the geographical, cultural, and ecological environment characters explore during the game.

By contrast the first edition of Advanced Dungeons \& Dragons is, to this day, among the most complex games in the genre. Not only does it have many more rules than its predecessor in the Dungeons \& Dragons brand, the rules pertain to far more detailed aspects of the depicted world. The combat system is more baroque, so much so that some rules governing combat are used by a vanishingly small proportion of those

Arneson and Gygax (1974). Jon Peterson (2012) is a definitive account of the prehistory of the genre.

Gygax sold his intellectual property rights to both games in 1985; the brands are currently owned by the game company Wizards of the Coast. The two classic games were overhauled in 2000 to such an extent they constituted a new game not readily compatible with prior editions; this new game was labeled the third edition of Dungeons \& Dragons. The two games were also merged, as Dungeons \& Dragons materials and Advanced Dungeons \& Dragons materials were no longer published separately. An earlier, far less extensive revision came in 1989 with publication of the second edition of Advanced Dungeons \& Dragons. A further significant revision came in 2008 as the fourth edition, and yet another major revision was released in 2015 as the fifth edition of Dungeons \& Dragons. Although the third, fourth, and fifth editions are called Dungeons \& Dragons, they resemble Advanced Dungeons \& Dragons more than the original Dungeons \& Dragons.

6 Gygax (1977, 1978, 1979). James Ward and Robert Kuntz (1980), which elaborates the role of divine beings within the game, is not strictly necessary as a sourcebook; it was officially sanctioned by Gygax, however, and these four books constituted the basis for the wave of popularity of Advanced Dungeons \& Dragons in the early 1980s. 
who play. ${ }^{7}$ This attention to detail, present in the original rules, increased over time. A second series of sourcebooks for Advanced Dungeons \& Dragons was published between 1985 and $1987 .{ }^{8}$ These books increased the detail of existing rules and added rules to govern previously undescribed or underdescribed domains of character action, such as mountaineering, mining, belaying, camping, and the effects of weather. So much new material was added during the mid-1980s, in fact, that games using these sourcebooks in addition to the original rulebooks became known as "edition 1.5" of the game.

Many of these new rules were first introduced in Dragon magazine, which (like the two classic role-playing games) was published by Gygax's company Tactical Studies Rules. Dragon debuted in the mid-1970s as a discussion forum for hobbyists interested in the new role-playing genre. ${ }^{9}$ Gygax's articles in the magazine enjoyed special status as quasi-official supplements to the material found in the official published rulebooks. He wrote a regular column for Dragon called "From the Sorcerer's Scroll", and he consulted with the editors about a recurring feature called "Sage Advice", in which the magazine would answer questions and adjudicate disputes about game rules. While the magazine covered games other than Dungeons \& Dragons and Advanced Dungeons \& Dragons, its success - indeed its existence - depended on the popularity of those games, in particular the latter. And the magazine was indeed successful, with a total run of 359 issues over more than thirty years before it ceased publication in 2007.

Among the most frequently recurring theme of articles and letters published in Dragon was the tension between two purportedly incompatible virtues in a fantasy game, which were labeled "realism" and "playability". ${ }^{10}$ The former consists in preserving laws of nature of the real world and describing a fictional setting in detail. The latter consists in being simple enough for players to understand a game's principles and mechanics and for game play to proceed without onerous recordkeeping or rulebook consultation. Gygax weighed in on this issue most explicitly in an essay titled "Realism v. Game Logic”, which appeared in Dragon in July $1976 .{ }^{11}$ In that piece the principal architect of the genre of role-playing games came down in no uncertain terms in favor of the position that, wherever they seriously conflict, the value of playability systematically supersedes that of realism.

One example is "weapon-specific armor class adjustments", where the combat effectiveness of a weapon used by an attacker varies depending on the type of armor worn by a defender. See Gygax (1978), 38.

See Gygax (1985), but note also Kim Mohan (1986), Douglas Niles (1986), and Jeff Grubb (1987).

The magazine was originally called The Dragon, but the name was later shortened to Dragon. It grew out of an earlier, even more specialized publication about military games called The Strategic Review.

10 A perennial problem was powers of illusion, which proved more difficult than other elements of heroic fantasy to capture with a playable game mechanic.

11 Gygax (1976). 
Gygax illustrated his claim with the simple mechanic, used in both classic versions of his game, for determining what happens when a character falls from a great height: the player rolls an ordinary six-sided die for each ten feet that the character fell to determine the number of hit points of damage the character sustains. (Hit points measure injuries a character can withstand before becoming incapacitated.) This example was well-chosen: subsequent issues of Dragon saw many attempts to replace this mechanic with a more complex variant, but the original mechanic is widely, and in my view correctly, regarded as superior to these alternatives.

Notwithstanding Gygax’s unequivocal stance favoring playability over realism, and his apt illustration with the central case of falling damage, his analysis of the tension in game design between realism and playability is too crude. This claim can be immediately motivated by noting that the first edition of Advanced Dungeons \& Dragons is widely regarded as the classic game of the role-playing genre even though it is among the least playable. One illustration is the game's system governing the use of magic spells, which is based on the milieu of Jack Vance's fantasy novels rather than on the arguably more playable system of spell points. ${ }^{12}$ In a spell point system a spellcaster has a given amount of magical power and each spell cast reduces this by a certain quantity, typically varying with the power of the spell, until the character is reaches zero spell points and so must restore them before performing further magic. In the Vancean system of Gygax's games, by contrast, characters with magical abilities memorize specific spells in advance, and their magic powers become depleted once they have used all these previously prepared spells. This Vancean system of magic is arguably less playable than a spell point system because it slows play: players are required to engage in advance planning, and both players and referees are required to do more recordkeeping. But the system's advantage is it is more realistic, in the sense relevant here, as it provides a richer backstory about the principles by which magic operates in the fantasy world.

On many points of difference between the two classic role-playing games, furthermore, the more complex system of Advanced Dungeons \& Dragons is superior to the simpler system of original Dungeons \& Dragons. There is far more material of a quasiscientific sort, explaining the abilities and cultures of different races (dwarves, elves, gnomes, and the like). ${ }^{13}$ Similarly there is much more material about abilities and habits of the monsters adventuring characters might encounter. ${ }^{14}$ One of the more popular reg-

12 Gygax discusses the influence of Vance on the principles of spellcasting in his games at Gygax (1979), 40. Vance began as a pulp writer in the 1940s, and over his career he published dozens of novels and stories. Most pertinent in the present context is the Dying Earth series of four fantasy novels; see Vance (1950, 1966, 1983, 1984). This material is found in various places but see especially Gygax (1978), 13-19, Gygax (1979), 15-16, and Gygax (1985), 7-13.

14 Gygax (1977) is the classic source here, but Turnbull (1981) and Gygax (1983b) also greatly expanded the amount of information available regarding creatures both fantastic and mundane. 
ular features in Dragon was the "Ecology of ..." series, wherein the behavior, life cycle, and natural history of a fantastic creature is explored.

In addition to the rulebooks and the discussions in Dragon, Gygax also published, mainly for use with Advanced Dungeons \& Dragons, specifics of the particular campaign setting that he used in his home game. This fantasy world was called "Greyhawk" after its most prominent city (also after a species of bird which flourished near that city). This setting was first detailed in the World of Greyhawk supplement. ${ }^{15}$ Many official published adventure modules included additional information about this world, and in time a new sourcebook appeared under the title Greyhawk Adventures. ${ }^{16}$ This material enabled a richer engagement with the world of a fantasy role-playing game than was previously available. Even though it was not part of the official game rules, this material was nevertheless crucial in further differentiating role-playing games from board games, for it enabled participants to develop a richer understanding of the sociology, natural history, and cosmology of a fantasy setting.

This material also made clear that despite its numerous fantasy elements, Gygax's game was grounded in the highly specific historical frame of Europe circa $1400{ }^{17}$ The various political domains of the Greyhawk setting were transparently based on those of late medieval Europe, and in some cases southwestern or central Asia. ${ }^{18}$ Furthermore the state of the art of military technology in the game fell in the narrow period after the longbow was widely used (mid-14 ${ }^{\text {th }}$ century) but before cannons were powerful enough to render castles obsolete (roughly the mid- $15^{\text {th }}$ century). ${ }^{19}$

Not all this detailed material improved the game; at times it introduced unnecessary complexity well understood as an unjustified loss of playability. In the later years of first edition Advanced Dungeons \& Dragons Gygax was accused, with some warrant, of failing to distinguish clearly enough between the rules of the game - which would apply whether a home game was set in Greyhawk or not - and the particular culture and history of his favored fantasy world, which might be replaced in a different campaign setting.

15 Gygax (1983a).

16 Ward (1988). Gygax also published novels set in Greyhawk; the series was later extended, with Gygax’s permission, by the writer Rose Estes.

17 In my view it is no coincidence that fantasy games and literature often involve the technology and political forms of the late middle ages. During that period of alchemists, empirical investigation yielded new control over nature but was not yet systematized into modern science (as was achieved by Galileo Galilei and Rene Descartes in the $17^{\text {th }}$ century). Those claiming powers to affect nature thus had more to offer than in prior eras, even though no clear distinction between magic and science had yet been marked. The tendency of horror-themed games and literature featuring psychic powers to be set in the late $19^{\text {th }}$ or early $20^{\text {th }}$ century may have a related explanation. In this case it is the advent of modern psychology (rather than that of modern science in general) which is imminent but not yet clearly distinguished from the supernatural. Gygax notes this already at Gygax (1976), 29.

19 Apart from its pure fantasy elements, the chief difference between Gygax's setting and the actual Europe of 1400 is the absence of monotheism. The setting resembles a world where Homeric religion survived through the manifold political and technological changes of the subsequent two millennia. 
Steve Jackson's Generic Universal RolePlaying System - better known as GURPS presented a rival to Advanced Dungeons \& Dragons mindful of this distinction. ${ }^{20}$ GURPS prizes playability in rule design by excluding information about setting altogether. The system enables the creation of characters and includes generic rules for combat but, unlike in Dungeons \& Dragons, these characters and combat rules can be adapted not only for different campaign settings but also for different genres of game. Fantasy games are marked by including magical spells, medieval weaponry, and beings like dragons and elves; other popular role-playing genres include science fiction, horror, superhero, and James Bond-style spy games. In GURPS nearly all realism is supplied by the setting rather than by the base game rules themselves. While GURPS never achieved the broad popularity of Dungeons \& Dragons, it has been highly successful and influential. The differences between GURPS (and other rival tabletop role-playing systems) and Dungeons \& Dragons brand games should not be exaggerated, however, since from the start GURPS included genre-specific supplemental materials; thus the same tradeoffs between realism and playability that arise in Dungeons \& Dragons also arise in GURPS and other role-playing systems. I focus on Dungeons \& Dragons brand games since they have been, in the history of role-playing, far and away the most popular and genre-defining.

As the success of GURPS and other highly playable games suggests, even defenders of the first edition of Advanced Dungeons \& Dragons should concede that it overreaches toward realism at the expense of playability. Rival systems and successors in the brand were correct to seek to streamline the game, even if the overall result in each case arguably overreached in the opposite direction. ${ }^{21}$ Nevertheless as an achievement of game design it is difficult to deny that Advanced Dungeons \& Dragons stands above more playable alternatives, the original Dungeons \& Dragons included, that it largely superseded. Accordingly we need an account of the tension between realism and playability which captures that fact. Such an account must not lose sight, however, of Gygax’s emphasis from "Realism v. Game Logic” that it is games we are discussing, not simulations or artworks, and that games are assessed in large measure by their playability. $^{22}$ In the next section I turn to political philosophy, in particular the work of John Rawls, for resources to help illuminate the tension between realism and playability.

20 Jackson (1986).

21 Even if first edition Advanced Dungeons \& Dragons is the superior game, it of course does not follow that it is to be preferred in all contexts. There are contexts where checkers is preferred to chess, after all, and where low art is preferred to high.

22 In a broad sense of the term, tabletop role-playing games do simulate a fantasy world. But crucially they do not seek to simulate experience of a fantasy world, a point I return to below. Both Juul (2005) and Miguel Sicart (2011, 2014) advance an understanding of games as simulations. Sicart understands simulations in contrast with mere representations (like photographs), in part because participants play an active role in generating a game. Tabletop role-playing games are simulations in this sense, since players are active creators of the worlds they 


\section{Realistic Utopia}

In the opening passages of On the Social Contract Jean-Jacques Rousseau famously enjoins political philosophers to "take people as they are, and laws as they might be". ${ }^{23}$ John Rawls, widely (and in my view rightly) regarded as the greatest political philosopher of the $20^{\text {th }}$ century, develops Rousseau's injunction into the idea of a "realistic utopia”. ${ }^{24}$ There is by design an air of paradox to this term, since it is nearly definitional of a utopian conception of politics that it is in some respects unrealistic. Rawls's realistic utopia is in a way not an exception, since it involves idealizations never fully satisfied in the actual world. But Rawls, like Rousseau before him, is concerned not to engage in political theorizing that is utopian in the pejorative sense, a mere flight of the imagination unclearly related to actual human affairs. In Rawls's view a theory of politics should be utopian in the sense of providing an ideal vision of society which may be used to evaluate the status quo and to establish priorities for reforming institutions. But in his view political theory should also be realistic by refraining from treating human psychology as itself up for reform. The basic contours of human psychology help to define politics, in Rawls's approach, and so are not subject to criticism by an ideal political conception. ${ }^{25}$ Thus we take people (or their broad psychological capacities and dispositions) as they are, and laws (or more generally societies and their institutions) as they might be when these laws are created and applied by those people.

In a late work Rawls writes: "There are two necessary conditions for a liberal conception of justice to be realistic. The first is that it must rely on actual laws of nature ... The second ... is that its first principles and precepts be workable and applicable to ongoing social and political arrangements." ${ }^{26}$ As I explain in this section, Rawls's "workability" is close kin to the "playability" of the Dragon magazine discussions (ironically enough), yet it is a constituent of realism as he understands it. This provides a clue that we may be able to understand playability as realism, and accordingly that we may be able to understand both playability and realism as aspects of the single value of realistic game play.

Rawls contends that a utopia must include a realistic understanding of what citizens are like and must also be realistically applicable by citizens themselves. These two constraints apply regardless of what sort of society the realistic utopia is to regulate, but in a democratic society the latter constraint takes on special significance. This is in part be-

fantasize. But the term "simulation" is more apt as a characterization of video games with strongly experiential components, since it connotes experience (as in the term "flight simulator", and the like).

23 Rousseau (1762), 46. I have re-translated "men” as "people” and "can" as "might”.

24 Rawls develops this idea explicitly at Rawls (1999), 11-16, and Rawls (2001), 4-5 and 12-14.

25 Rawls charges Karl Marx with utopian overreach on just this point; see Rawls (2001), 157-158. For those interested in learning more about Rawls's theory, Samuel Freeman (2007) is a very fine exposition. Among Rawls's own works the best entry point, in my judgment, is Rawls (2001).

26 Rawls (1999), 12-13. 
cause the ambit of citizenship in a democratic society is wide: there are no legal slaves or subordinate castes, and there is no legal restriction on political power due to sex, race, or ethnicity. ${ }^{27}$ Furthermore in democratic societies the entire citizenry is treated as competent to contribute to the shaping of laws and other major social institutions, and political offices are determined by competitions open to all citizens. Thus everyone, or at least all competent adults, must be able to understand and apply standards articulated by an ideal conception of society. The wide ambit of citizenship, when coupled with openness in principle of offices to all citizens, makes the constraint of "workability" especially pressing in a democratic society. There is no space for a restricted class of priests, functionaries, aristocrats, or bureaucrats who understand the prevailing conception of justice and apply it to the citizenry at large.

Of greatest interest for present purposes is that Rawls regards this workability as itself a constraint of realism. The first aspect of Rawlsian realism is to have an accurate, systematic, and rich portrayal of what people are like, including in particular their social psychology. The second is to have an articulated ideal conception of society that is clear and simple enough for people to use as they create, reform, and apply laws. In a democratic society there is an especially close connection between these two constraints: since all citizens are to participate in the creation, reform, and application of laws, both elements of Rawlsian realism mainly concern general facts of human social psychology.

Rawls uses this frame to evaluate competing ideal conceptions of society. "No political conception of justice could have weight with us," Rawls writes, "unless it helped to put in order our considered convictions of justice at all levels of generality." ${ }^{28}$ Such a conception "is a way of continuing public discussion when shared understandings of lesser generality have broken down ... we look to the fundamental ideas implicit in public political culture and seek to uncover how citizens themselves might, on due reflection, want to conceive of their society." 29 The role of an ideal conception of justice is accordingly like that of the rules of a game. Much of the time this conception is present but implicit; it is invoked explicitly only when conflict or uncertainty arises about how to proceed. But for this to be the conception's use, then (as with players in a game) participants in the activity - in this case the democratic citizenry - must be able to understand the conception and apply it to concrete circumstances.

In particular Rawls considers the prospects, in light of human psychology, for each ideal conception to sustain and perpetuate itself through the technological, cultural, and

\footnotetext{
27 Even the presence of large numbers of foreign nationals is a potential problem in a democratic society, since it introduces a body of individuals who are subject to a society's laws but lack the status to participate meaningfully in the formulation and application of those laws. 
generational changes characteristic of human societies. ${ }^{30}$ In Rawls's approach the extent to which an ideal conception of justice would be freely accepted by subsequent generations, once this ideal is established, is tantamount to a criterion of adequacy of that ideal. According to Rawls's plausible working understanding of social psychology, people tend to freely accept a conception of society to the extent they experience participation in a society regulated by that conception as sincerely cooperative. ${ }^{31}$

Rawls does not develop a political theory for non-democratic societies, but even there his constraints of realism apply. In such cases there is less unity between the two elements of Rawlsian realism, since laws in non-democratic societies apply to everyone but are created and applied by only a privileged class. Nevertheless a single frame of understanding - realism as a constraint on utopia - captures both these sorts of desiderata on a theory. For Rawls it is vital that the ideal conception used as a standard of criticism be one that is appropriate to human societies, to the social world of beings characterized by human nature as we know it. This is because in his view this ideal's existence serves not only to help criticize the status quo but also to reconcile us to the fact of our humanity. However bad the status quo (or its etiology) may be, in Rawls's view there is room for hope rather than despair so long as there is a worthy ideal appropriate for us. ${ }^{32}$ A Rawlsian realistic utopia thus aims to unify the functions of social criticism and social reconciliation, with both functions filled by a single ideal political conception. Armed with these ideas from Rawls's approach to political philosophy, I return in the next section to tensions between realism and playability in the design of fantasy games.

\section{Playability as Realism}

Almost all discussions of the tension between realism and playability in game design, including in the pages of Dragon, treat these as independent and competing values. Thus the frame of discussion is not about how to synthesize or unify these values, but instead concerns which should take precedence when inevitable tradeoffs between them arise. It is difficult to develop a greater understanding or appreciation of the merits of competing positions when they are juxtaposed this way. Different people are attracted to different weightings of the competing values, and so form different judgments about which tradeoffs are to be accepted and which are not. But absent a more abstract overarching value which subsumes competing values, or (more generally) absent a broader theoretical framework within which to situate competing claims, it is difficult to illuminate these conflicts, much less to resolve them.

This idea appears in various places in Rawls’s work; see, for one important example, Rawls (2001), 180-181. For a fuller discussion see Garthoff (2016).

31 This idea pervades Rawls's work, but the fullest statement of his conception of human psychology is found at Rawls (1971), 453-512.

32 See Rawls (2001), 3-5. Also relevant is Rawls (1993), 101 and 171-172. 
As was explicated in the previous section, Rawls regards both having a rich, systematic, and accurate account of the people governed by a system and having a system simple enough to be understood and applied by people as aspects of realism. This connection suggests a different frame for disputes about tradeoffs between realism and playability in fantasy games. Instead of regarding realism (having complete and coherent laws of nature) and playability (workability) as two independent values often in competition, we might instead apply Rawls's idea and seek to understand each as an aspect of realism in a broader sense. The hope is that doing so engenders richer understanding of the values at stake in game design, both to illuminate what is at stake in these disputes and to inform judgment about which of these values to privilege when tradeoffs between them are necessary.

The tight connection between complete laws of nature and workability in democratic theory - that both are largely sub-domains of human social psychology - is not available in this case. There are at least two important reasons for this. One is that tabletop role-playing games in general, including the classic examples discussed here, typically lack democratic administrative structures. Normally there is an individual - in the Dragon discussions variously termed "judge”, "referee”, "game master”, or “dungeon master" - with autocratic authority regarding the rules. ${ }^{33}$ All other participants are subject to this individual's rulings, and have no avenue of appeal other than back to the same authority. This authority is explicitly understood to extend not only to interpretation of official rules and creation of new rules, but also to the suspension or alteration of official rules. The cooperativeness of game play accordingly rests principally on this person's knowledge of the rules, skill when interpreting and extending them, and ability to apply them fairly and consistently. The only recourse participants have is to exit the game. $^{34}$

The second important reason why there is more distance between the two elements of realism in the context of games is that fantasy settings typically involve significant departures from the laws of nature of the actual world. In the classic versions there are immortal (though not omnipotent) divine beings who grant powers to their devotees, there are incantations which harness magical forces to affect minds and alter nature, and there are fictional races and species of both humanlike and decidedly non-human sorts.

33 Gygax advises referees on this point as follows: "The game is the thing, and certain rules can be distorted or disregarded altogether in favor of play. Know the game systems, and you will know how and when to take upon yourself the ultimate power.” See Gygax (1979), 9. This passage appears in the introduction to the original Dungeon Master's Guide, and so is among the most authoritative sources about the game. I tend to think Gygax overstates this point, and that fidelity to the rules importantly constitutes the gameplay as cooperative rather than as, say, a manipulation of the players by the referee. But Gygax is clearly cognizant of the fact, important here as in legal theory, that fetishizing rules seldom makes for judicial excellence.

34 Rawls emphasizes that the analogous point does not hold in the political case; people do not in general enter societies voluntarily and do not in general have the ability to exit their societies. In Rawls's view this entails that societies should be understood within a political theory as involuntary social structures rather than as voluntary associations. See Rawls (1971), 13. 
Thus realism here does not mean complete fidelity to the actual laws of nature, but instead means having a rich and systematic accounting of the laws of nature of a fictional world. But generally speaking it serves realism to minimize departure from actual laws of nature, since actual laws provide a realistic coherence difficult to recover through more thoroughly fictional laws and principles.

Thus in role-playing games the first aspect of realism concerns the metaphysical and quasi-scientific principles of a game's fictional setting and the social scientific principles of its many denizens, including especially the characters portrayed by the players of the game. By contrast the second aspect is realism about the (human) players who create, interpret, and apply the rules of the game; this includes especially the referee, but also the other participants, since the success of the game depends on how they experience it. Both are aspects of realism in the relevant sense, for both place limits on the games players are apt to experience as cooperative and fulfilling.

Notwithstanding this difference between political theory and role-playing games, Rawls's conception of realism can still be deployed to help unify realism and playability as constraints on fantasy. Each is a way of being real about what can be accomplished, also more strongly about what should be aspired to. The connection between these two modes of realism is not captured by thinking merely as follows: we are attempting to articulate a rich and systematic world, and we are attempting to play a game, so sometimes we must limit the completeness of our world in the interest of having a playable game. Better is to think: we are attempting, through the rules and play of a game, to articulate a rich and systematic world, and so we must aspire only to the richness and systematicity compatible with a playable game. To aspire to more than this would be utopian, akin to articulating a conception of society which is satisfying to the imagination but unsustainable given human social psychology. To aspire to less than this - permitting arbitrary, ad hoc, or contradictory rules or laws of nature - would be unrealistic, not because such rules are unplayable but because they fail to articulate a convincing world.

Note that on this understanding there are still tradeoffs between, and there is room for disagreement about the relative importance of, realism and playability. These tradeoffs also arise in political theory: Rawls rejects Amartya Sen's use of capabilities as a currency of distributive justice, for example, largely because he thinks individuals and institutions cannot discern these. ${ }^{35}$ This view privileges the realism of workability over the realism of a more detailed understanding of human nature, since it gives up on a fact otherwise relevant to justice on the ground that appealing to this fact is unworkable. The way these two constraints of realism operate, however, is not intuitionistic; the

35 See Rawls (1999), 13, and Rawls (2001), 168-176. See also Sen (1987, 1992), Martha Nussbaum and Sen (1993), and Nussbaum (2000). 
values of workability and realism are not understood as independent. ${ }^{36}$ Instead the overarching aim of realistic utopia guides judgment about tradeoffs: greater realism about people (tracking their capabilities to convert resources into happiness) is excluded, since it comes at the expense of a system realistically implementable by people (who are limited in their ability to discern capabilities). The tradeoff here is not between two wholly independent goods. It is rather a tradeoff between two goods, each of which partially constitutes the same larger good.

In "Realism v. Game Logic", Gygax articulates a similar point with respect to decisions he made about the design of Dungeons \& Dragons. Both Dungeons \& Dragons and Advanced Dungeons \& Dragons use combat systems in which an entire minute of combat is encapsulated in a few throws of the dice, even though a minute of hand-tohand combat using medieval weaponry might involve dozens of feints, parries, and attempted strikes. He writes: "Protracted combat situations which stress 'realism' will destroy the popularity of the game ... players desire action, but all except the odd few will readily tell you that endless die-rolling to determine where their character will defend against an attack, and so on, are the opposite of action; they are tedious." ${ }^{37}$ There is considerable wisdom in that observation, but Gygax again overstates his case. In that same essay Gygax decries rules about weapons expertise as an example of "foolish misconceptions that periodically crop up". ${ }^{38}$ Yet a mere two years later, with the publication of the Advanced Dungeons \& Dragons Players Handbook, Gygax incorporated rules concerning proficiency using different weapons. ${ }^{39}$ There is an appropriate pressure in game design toward developing a realistic fantasy world, and Gygax himself responded to this pressure even in some cases where it stood in tension with playability.

\section{Game Balance as Playability}

In the previous section I discussed how Rawls's combination of workability and fidelity to laws of nature as aspects of a single value of realism in political philosophy may be used to illuminate conflicts between playability and realism in game design. In this section I continue this discussion by focusing on a specific issue, which Gygax calls "game balance". As Gygax uses this term, it refers to the specific constraint that different sorts of characters available in a role-playing game be roughly equal in skills and powers. ${ }^{40}$ Thus if one character is a warrior-type with special combat skills, then that character should have little or no ability to use magic; similarly those who use magic should typically have a diminished effectiveness when fighting. Another example is that

36 See Rawls (1971), 34-45.

37 Gygax (1976), 30. The emphasis is Gygax’s.

38 Gygax (1976), 30.

39 Gygax (1978), 19.

40 The term "game balance" is used much more broadly in today's literature on game design; but it descends from Gygax, and he uses it in the far narrower sense articulated here. 
members of nonhuman races typically have certain abilities, such as ability to see in the infrared spectrum, which human characters lack; but partly for this reason nonhuman characters are generally more limited in the upper bound of skills they develop. This constraint was explicitly understood by Gygax to apply not during each stage of an adventuring career, but rather over its entire course. Wizards were by design less powerful than warriors at the start of play but more powerful if they survive to later stages of the game. (Interestingly Rawls makes the parallel point about distributive shares in his theory of justice: these are to be assessed over the course of an entire human life, and not by any snapshot of the distribution at a particular moment in time. ${ }^{41}$ )

Game balance is an aspect of playability. Understood simply as the products of an imaginative exercise, denizens of a fantasy world need not have roughly equal potential as adventurers. ${ }^{42}$ But this is a crucial constraint on the design of role-playing games, for it is vital that the game is experienced as cooperative by the players. This constraint is thus, in Rawls's sense, a constraint of realism. To be successful the game must be experienced as fair and cooperative by its participants, given the basic facts of human social psychology. Game balance is normally needed for this; if different character types differ radically in power, players with weaker characters will characteristically experience the game as less fulfilling and cooperative. In addition this game balance must not only obtain, it must be manifest in the sense that we expect, in light of human psychology, that players will pick up on it and appreciate it. ${ }^{43}$ Thus there is pressure toward equality of power in role-playing games, just as there is pressure toward equality of power in the ideals of democratic politics. The former is not as strong as the latter, since games are characteristically voluntary. But in each case any limits on equality are best understood partly relative to human psychology, justified in part by what people are expected to experience as cooperative or fulfilling.

It is interesting to contrast Gygax's two illustrations of this principle in the "Realism v. Game Logic" essay. He asks: "Why can’t magic-users employ swords? And for that matter, why not allow fighters to use wands and similar magic devices? On the surface this seems a small concession, but in actuality it would spoil the game." 44 In my view the latter example is much stronger than the former, and the connection between realism and playability helps to explain why. Fighters (or warriors) should not in general have

41 Rawls (1971), 175-183.

42 Hence there is no direct analog to this constraint within the domain of fantasy literature.

43 Certain unofficial but commonly permitted character races, such as gully dwarves and half-goblins, are by design weaker than other races, and some players enjoy the underdog status which accompanies playing these characters. But in practice most players are not interested in such inferior options. At the other end of the spectrum Gygax cautions referees against permitting powerful non-anthropoid monsters to be played as characters. The desire to play such creatures is understandable, as they commonly have powers well beyond those available to beginning characters. But these creatures tend not to develop their powers over time, and so as 
use of wands or similar magic devices not only because permitting that could disrupt game balance, but also because there is no important rationale internal to the filling out of a fictional world which calls for this. It is commonplace in fantasy literature for access to magic to be limited to those who have spent years studying, in part because this is a more realistic way of conceiving the fantasy. Thus in this case playability (game balance) and realism (rich and systematic world-explication) point in the same direction. By contrast, Gygax's rule that magic-users (or wizards) literally cannot wield swords, a frequent object of disdain or incredulity in letters to the editor of Dragon, was a mistake. This rule is not necessary for game balance, since making magic-users significantly less effective in the use of swords achieves the same goal; and since these magicians have been studying arcane arts rather than swordplay, this diminished effectiveness is independently realistic. ${ }^{45}$ What sort of world is conceived, by contrast, if a human wizard is literally incapable of wielding a sword in combat? This is unrealistic, and so other rules should be used to achieve the desired game balance. The overarching value of players realistically constructing and conceiving a world, in other words, favors a different solution to the playability problem in this case.

Although not usually defended in these terms, another way Gygax wisely took account of playability considerations in his game design is by making "critical hits" (attacks automatically resulting in massive damage), and more generally attacks that might result in instant character death, relatively rare. ${ }^{46}$ Inclusion of such attacks is no obstacle to playability in the short term, as a mechanic for determining when an attack produces instant death need not be cumbersome. But constant vulnerability to immediate death obstructs playability in a broader sense, since it requires players to create new characters frequently and also serves as a disincentive to players becoming invested in their characters.

\section{Realistic Worlds versus Realistic Experiences}

As a further illustration of how Rawls's account of realism illuminates tradeoffs between playability and realism in game design, consider what may have been the most contentious point of discussion in Dragon during the 1980s: that the rules of first edition Advanced Dungeons \& Dragons disadvantaged female characters by setting their maximum strength score lower than that for male characters. Endless letters were published either criticizing this feature of the game as unnecessarily alienating (a playability

45 The weapon proficiency rules of Advanced Dungeons \& Dragons already achieve this, and so make the absurd rule that wizard-types literally cannot use swords not only unrealistic but unnecessary. Within the less realistic rules of the original Dungeons \& Dragons, by contrast, an ad hoc rule imposing penalties on non-warriors when using certain weapons would be needed. 
consideration) or defending it as a realistic reflection of lawlike differences between the sexes.

In view of the overriding aim of constituting a cooperative and fulfilling activity, this feature of the rules of first edition Advanced Dungeons \& Dragons constitutes a major flaw; and the charge that the rule is relatively unplayable because unnecessarily alienating diagnoses well its objectionable character. ${ }^{47}$ As was frequently noted in Dragon, the game is a fantasy. Even if such a fact obtains in a lawlike way in the actual world it is not essential to carry it into a world that contains gods, monsters, and magic. Realism about players is more significant than realism about characters in this case, as a constituent of the overarching aim of constructing a realistic fantasy through the medium of a role-playing game.

That said, it seems to me not similarly objectionable to have sex-differentiated strength maximums if these are clearly compensated by advantages to female characters of a comparable magnitude. (Moreover I would say appropriate compensation in this case is fairly clear: female characters should have a higher maximum score for constitution, which in the game measures overall health and vigor. This would reflect the fact that in the actual world human females are less susceptible to death and disease at each stage of life.) There would then be no advantage to playing one sex rather than another, so the differentiation as such need not inhibit game balance or cooperativeness. There are already differences in profession and race which define characters in profoundly different ways. In such a context having a relatively minor difference grounded in sex need not greatly affect the success of the characters or the relative status of the sexes within the game. The rationale for such a sex-differentiated approach would be to minimize departures from the actual world in the natural laws governing character abilities. There is of course no problem with a game system which assigns equal maximum strength scores to female and male characters, but it is easier to develop a rich and systematic world if as much of the actual world is preserved as is compatible with the changes necessary to effect the fantasy.

This example also illustrates that there is an important issue of how realism constrains fantasy distinct from the issue of realistic simulated experiences in video games. ${ }^{48}$ The appeal of tabletop role-playing games is not, and has never been, that they enable us to simulate unusual and interesting experiences. Their appeal - which remains considerable - is rather that they enable us to conceive unusual and interesting worlds.

47 This parallels Rawls's assessment of ideal conceptions of society by the extent to which they discourage alienation; see Rawls (2001), 130-132

48 Juul (2005) provides helpful conceptual resources for marking these distinctions across a wider array of games. He regards tabletop role-playing as a borderline case of a game, however, and so does not discuss issues of realism in such games; see Juul (2005), 44. He is also concerned mainly to describe aspects of games and their tradeoffs, rather than to inform judgment about how best to manage these tradeoffs in the design (or the play) of games; see especially Juul (2005), 163-196. 
When we conceive worlds, it helps if they are rich and systematic, if their internal laws of nature (the metaphysical and quasi-scientific principles which constitute and govern them) are full and cohesive. But it also helps if these principles are simple enough that we can readily understand them, and well-organized enough that we can use them before we achieve full familiarity with them.

Gygax fails to mark this distinction with precision. Much of his contempt for advocates of realism in the "Realism v. Game Logic" essay derives from characterizing the value of realism as that of simulated experience. Understood this way, he is surely correct that tabletop fantasy role-playing is a game and not a simulation, and accordingly that 'game logic' takes systematic precedence over realistic simulation. But those who complain wizards should have some ability to wield swords need not be, and characteristically will not be, motivated by concern that the game is a less effective simulated experience when rules prohibit this. This complaint concerns the nature of the world conceived and created through the ongoing activity of the players and referee, and its substance is that this world is less realistic - and the game less fulfilling - when it is constituted by arbitrary or unmotivated rules.

Gygax's evident pride in the coherence of the rules of Dungeons \& Dragons indicates he values this sort of realism. ${ }^{49}$ That he is sole author of that most majestically unplayable game, Advanced Dungeons \& Dragons, also indicates this. Gygax sells short his greatest achievement when he writes: "Gaming is a form of play. Games are usually for diversion or amusement." 50 The former is a truism in need of development and elaboration. The latter understates both the grandeur of Advanced Dungeons \& Dragons as a creative achievement and the principal design innovation of the game: namely, that it unleashes the creative potential of participants in a way previous game genres did not. ${ }^{51}$ Understood merely as a diversion or amusement, Advanced Dungeons \& Dragons is elaborate and inefficient. By that standard it is surely inferior to many other fantasy role-playing games, and inferior to many games of different genres. A far less realistic game - such as the gothic-themed Vampire: The Masquerade, which briefly surpassed Advanced Dungeons \& Dragons in sales during the nadir of the latter game's popularity in the 1990s - might be superior by this standard. ${ }^{52}$ But Gygax’s achievements merit a far more special place in the history of games, as he observes with his rather immodest placement of Tactical Studies Rules alongside "the creators of chess (whoever they were), miniature wargames (H. G. Wells), and board wargames (thank you, Avalon Hill!)" ${ }^{53}$ Gygax shows how a complicated framework - of both game rules and quasi-

\footnotetext{
Gygax (1976), 28-29.

Gygax (1976), 28.

Thus, as was noted above, his games are not mere representations in the sense Sicart (2011, 2014) uses.

Mark Rein-Hagen (1991).

Gygax (1976), 28.
} 
scientific materials like those found in his Greyhawk setting - could be appreciated by players and referees alike. But more importantly, he inaugurated a genre of game that enables players and referees to build on his and other worlds, both by tweaking and elaborating the rules and by spinning out stories that are made far more gripping by the realism of the worlds in which they transpire. Since this realism is achieved through the play of a game, however, it is also constituted in part by the game's playability. This latter constituent is realism about the people who play.

\section{Conclusion}

In this essay I have discussed how realism constrains fantasy. I have focused on games, using the tension between realism and playability in role-playing games (discussed in Dragon in the 1970s and 80s) as a principal context of discussion. I have used John Rawls's conception of a realistic utopia in political philosophy to illuminate that discussion. In particular I have explained how Rawls's dual constraints of workability and preserving the laws of nature can be adapted to unify the constraints of realism and playability beneath the overarching value of cooperation in the creation and conception of realistic fantasy worlds through the medium of role-playing games. I have also explained how these aspects of realism are distinct from what is sometimes discussed under the same label in the theory of games, namely realism of simulated experience, and accordingly how tabletop role-playing differs crucially as an activity from both liveaction role-playing and realistic video games.

\section{References}

Arneson, Dave and Gary Gygax (1974). Dungeons \& Dragons. Tactical Studies Rules, 1974.

Flanagan, Mary (2009). Critical Play. MIT Press, 2009.

Frasca, Gonzalo (2008). “Make a Point and Score Ten Thousands: Learning from Serious Games”. In Mirror Images: Popular Culture and Education. Counterpoints Vol. 338. Peter Lang AG, 2008.

Freeman, Samuel (2007). Rawls. Routledge Publishing, 2007.

Garthoff, Jon (2016). “Rawlsian Stability”. Res Publica 22:3, 2016.

Grubb, Jeff (1987). Manual of the Planes. Tactical Studies Rules, 1987.

Gygax, Gary (1976). “Realism v. Game Logic”. In Best of Dragon Vol. II. Tactical Studies Rules, 1981. (1977). Monster Manual. Tactical Studies Rules, 1977.

(1978). Players Handbook. Tactical Studies Rules, 1978.

(1979). Dungeon Masters Guide. Tactical Studies Rules, 1979.

(1983a). World of Greyhawk. Tactical Studies Rules, 1983.

(1983b). Monster Manual II. Tactical Studies Rules, 1983.

(1985). Unearthed Arcana. Tactical Studies Rules, 1985.

Jackson, Steve (1986). Generic Universal RolePlaying System. Steve Jackson Games, 1986.

Juul, Jesper (2005). Half-Real. MIT Press, 2005.

Mohan, Kim (1986). Wilderness Survival Guide. Tactical Studies Rules, 1986.

Niles, Douglas (1986). Dungeoneers Survival Guide. Tactical Studies Rules, 1986.

Nussbaum, Martha (2000). Women and Human Development. Cambridge University Press, 2000.

Nussbaum, Martha and Amartya Sen (1993). The Quality of Life. Oxford University Press, 1993.

Peterson, Jon (2012). Playing at the World. Unreason Press, 2012.

Rawls, John (1971). A Theory of Justice. Harvard University Press, 1971. 
(1993). Political Liberalism. Revised Edition. Columbia University Press, 1995.

(1999). The Law of Peoples. Harvard University Press, 1999.

(2001). Justice as Fairness. Harvard University Press, 2001.

Rein-Hagen, Mark (1991). Vampire: The Masquerade. White Wolf Publishing, 1991.

Rousseau, Jean-Jacques (1762). On the Social Contract. Trans. Judith R. Masters. Ed. Roger D. Masters.

St. Martin's Press, 1978.

Sen, Amartya (1987). Commodities and Capabilities. Oxford University Press, 1987. (1992). Inequality Reexamined. Harvard University Press, 1992.

Sicart, Miguel (2011). “Against Procedurality”. Game Studies 11, 2011. (2014). Play Matters. MIT Press, 2014.

Turnbull, Don (Ed.) (1981). Fiend Folio. Tactical Studies Rules, 1981.

Vance, Jack (1950). The Dying Earth. Hillman Publishing, 1950. (1966). The Eyes of the Overworld. Ace Books, 1966. (1983). Cugel's Saga. Timescape Publishing, 1983. (1984). Rhialto the Marvellous. Brandywyne Books, 1984.

Ward, James M. (1988). Greyhawk Adventures. Tactical Studies Rules, 1988.

Ward, James M. and Robert J. Kuntz (1980). Deities and Demigods. Tactical Studies Rules, 1980. 